\title{
nature
}

\section{Hubris, benefits and minefields of human cloning}

One man's absurdities are a gift to witless stereotypers of scientists. They are also an unwelcome stimulus to much needed consideration of the realities and implications of an uncomfortable technology.

E leven years ago, a group of Argentine scientists wrote to Nature complaining about the way in which a US research group had chosen to carry out unauthorized experiments in their country using a rabies-vaccine recombinant virus on cattle (see Nature 324, $610 ; 1986)$. The event caused a worldwide furore, not least because of the suspicion that the US researchers were taking advantage of a more relaxed regulatory system to carry out experiments that would have been refused permission at home. The experiments were quickly terminated. But they remain deeply entrenched in institutional memories, and have played an important part in ensuring that close - perhaps excessive - attention is given to safety issues in debates about the UN Biodiversity Convention.

Argentina's experience is directly relevant to the issues facing politicians and civil servants as they struggle to respond to the challenge thrown down last week by Richard Seed, the Chicago fertility enthusiast who claims to be about to carry out experiments in human cloning. One of the many arrogant statements produced by Seed was that, if prevented from carrying out these experiments in the United States, he would merely do so abroad, possibly in Mexico. The naivety of his belief that he will be able to find any responsible government prepared to offer him shelter from the opprobrium of the world's political and religious leaders (or indeed the doggedness of the world press) is matched only by the hubris with which Seed appears to have brushed aside the daunting technical obstacles that confront any attempt at safe and successful human cloning.

Whatever Seed's real capacities may be (and it is perhaps significant that at least one influential figure in the American Physical Society has been at pains to distance himself from any description of Seed as a physicist), with friends like him, human cloning has little need of enemies. Indeed, even if the most determined opponents of cloning had sought to invent a caricature of the 'mad scientist' encapsulating their greatest fears, they would probably have had qualms about writing some of the things that Seed has said for fear of destroying all credibility. The possible benefit of Seed behaving in the way that he has is that it has reawakened an awareness of the need for political action that had lost its way since an initial flurry last year, in the wake of the birth of the cloned lamb Dolly (see page 218). The undoubted disadvantage is that his excesses have enhanced polarization in the debate, encouraging a reflex response that demands sweeping bans rather than the determined reflection that the issue deserves.

\section{Distinctions}

There are important distinctions to be drawn within the cloning debate that must be addressed if the many beneficial possibilities opened up by work at the Roslin Institute and elsewhere are not to be stifled (as some of the rules on, for example, embryo research and the use of fetal tissue in the United States have already done). These include the regeneration of diseased or damaged tissue and body parts made possible by more thorough knowledge of the techniques needed to manipulate the expression of the genes responsible for organ development. To include all such possibilities under the simplistic and now dangerously emotive label 'human cloning' undermines any reasoned debate on where a line should be drawn between what is and what is not acceptable, and in what circumstances.

Such distinctions are essential. Regrettably, to some there is as much arrogance behind the factual statement that a human clone is little different from an identical twin as there is in the demand that no human cloning research should be permitted. Again, deliberate and considered reflection is required. Think, for a moment, of the implications of the knowledge that an individual is a genetically identical copy of a parent. One does not need to make hand-waving appeals to abstract ideas of 'human dignity', or even delve into the realms of psychoanalysis, to appreciate that although some are relaxed about such a possibility, that feeling is far from universal. Regardless of the limits of genetic determinism, there are thoughtful — not to say influential — people for whom full human cloning is a moral and emotional minefield that should place it among taboos such as cannibalism or incest.

\section{Consent}

Declarations at the national or international level have their place, particularly in strengthening the willingness of signatory governments to resist bullying and demagoguery, religious or otherwise. But the value of purely legislative action, as even many supporters admit, is limited. Laws will ultimately be effective only if they are rooted in the consent of individuals and if that consent is, in turn, based on a realistic assessment of both the scientific possibilities and social pitfalls of cloning.

Detailed exploration of both is needed. The first because the potential medical benefits are such that it would be verging on the immoral not to attempt to find out what, and how achievable, these might be - just as a proper understanding of the science behind biodiversity is important for an effective preservation strategy (see page 215). The second because it is essential (and not only for the health and credibility of the biotechnology industry) that society develops regulatory instruments sufficiently sensitive to distinguish between the responsible and the irresponsible application of whatever knowledge emerges.

There are signs that such exploration is beginning. Britain's Human Genetics Advisory Commission is due to produce a discussion paper within the next few weeks, said to propose the circumstances in which some forms of cloning-related research should be allowed to proceed. In the United States, similar debates are being held within professional medical societies (though so far there remains reluctance to grasp them firmly elsewhere, for example on the National Bioethics Advisory Committee). Human cloning is not the most pressing issue facing our health-care systems, or indeed, our religious or political leaders. But the way we handle it provides a measure of our maturity in addressing critical issues at the intersection between the research community and the society which has to confront the uncomfortable truths and capabilities that research can yield. 